\title{
Causes of Upper Gastrointestinal Bleeding on Endoscopy in Tertiary Care Hospital
}

\author{
Muhammad Amir ${ }^{1}$, Sarah Hafeez², Muhammad Adrees ${ }^{3}$, Amir Nazir ${ }^{4}$, Hafiz Mughees Athar ${ }^{5}$ \\ 1,3,5Department of Medicine, Faisalabad Medical University, Faisalabad-Pakistan, ${ }^{2 D}$ epartment of Medicine, Allied Hospital, Faisalabad-Pakistan, ${ }^{4}$ Department of Medicine, Sargodha \\ Medical College, Sargodha-Pakistan
}

\section{ABSTRACT}

Background: There are multiple causes of upper gastrointestinal bleeding including portal hypertension, peptic ulcers, Mallory-Weiss tear, vascular anomalies, gastric neoplasms, erosive gastritis and erosive esophagitis. Objectives: To study the common causes of upper gastrointestinal bleeding on endoscopy in patients presenting in Tertiary Care Hospital. Study Design: Descriptive, cross-sectional study. Settings: Department of Medicine, Allied Hospital, Faisalabad Pakistan. Duration: $4^{\text {th }}$ April 2018 to $3^{\text {rd }}$ October 2018. Methodology: Patients with hematemesis and/ or melena of any age or gender, with single or multiple episodes of upper gastrointestinal bleeding were included. Enrolled patients were advised to stay NPO for 6 hours and then were brought to endoscopy room of Allied Hospital, Faisalabad. After sterilization endoscope was introduced via oral cavity of the patient and the cause of bleed was diagnosed. All the data was entered in the study proforma. Results: Total 352 patients were enrolled and their mean age was $43.76 \pm 13.93$ years. Majority of the patients i.e. 204 (57.95\%) were between 20 to 45 years of age. Out of 352 patients, $239(67.90 \%)$ were males and $113(32.10 \%)$ were females. The common causes of upper gastrointestinal bleeding were found to be variceal bleeding in 183 (51.99\%), peptic ulcer in $84(23.86 \%)$, Mallory-Weiss tear in 41 (11.65\%), vascular anomalies in $11(3.13 \%)$ and gastro-duodenal erosions in 33 $(9.38 \%)$ patients. Conclusion: This study concluded that variceal cause is the most common cause of upper gastrointestinal bleeding followed by peptic ulcer and Mallory Weiss tear.

Keywords: Upper gastrointestinal bleeding, Variceal bleeding, Peptic ulcer.

Corresponding Author

Submitted for Publication: 18-09-2019

Dr. Muhammad Amir, Assistant Professor, Department of Medicine, Faisalabad Medical University, Faisalabad-Pakistan

Email: dr.aamer78@gmail.com

Citation: Amir M, Hafeez S, Adrees M, Nazir A, Ather HM. Causes of Upper Gastrointestinal Bleeding on Endoscopy in Tertiary Care Hospital. APMC 2020;14(3):263-7.

\section{DOI: $10.29054 / A P M C / 2020.695$}

\section{INTRODUCTION}

Upper gastrointestinal bleeding is one of the most common causes of hospitalization in medical emergencies worldwide and has a high mortality and morbidity rate. Upper gastrointestinal bleeding refers to gastrointestinal blood loss whose origin is proximal to the ligament of Treitz.,

According to estimates from U.S. studies, nonvariceal upper gastrointestinal bleeding results in 400,000 hospital admissions per year, costing more than $\$ 2$ billion annually. It has been associated with increasing nonsteroidal anti-inflammatory drug (NSAID) use and the high prevalence (64 percent) of Helicobacter pylori infection in patients with peptic ulcer bleeding. ${ }^{3}$ Upper gastrointestinal bleeding is twice as common in men as in women and increases in prevalence with age. ${ }^{4}$ Despite advances in therapy, the in-hospital mortality rate remains high (13 percent) and rebleeding is common (15 percent). ${ }^{5,6}$

Commonly it presents with hematemesis (40\% to $50 \%$ ) and melena $(70 \%$ to $80 \%$ ) while hematochezia (which mostly has colonic origin) can present with fresh blood loss of up to 1000 $\mathrm{ml}$ which accounts for up to $10 \%$ of cases. ${ }^{7}$ Although upper gastrointestinal bleeding is self-limiting in majority of the cases yet every patient with upper gastrointestinal bleeding must be properly evaluated and undergo endoscopy for diagnostic purposes as well as therapeutic endoscopy if needed. There are multiple causes of upper gastrointestinal bleeding including portal hypertension, peptic ulcers, Mallory-Weiss tear, vascular anomalies, gastric neoplasms, erosive gastritis and erosive esophagitis. Peptic ulcers remain one of the leading cause of upper gastrointestinal bleeding in West accounting up to $40 \%$ while portal hypertension being second leading cause with 10 $20 \%$ incidence. $^{8}$

While according to a study conducted in Egypt, variceal causes of bleeding were the most common representing $70.1 \%$ followed by non-variceal causes $26.1 \%$ and obscure causes 3.8\%. ${ }^{9}$ According to various other studies the 1 year rate of variceal bleeding is $12 \%$. Frequently Upper $\mathrm{Gl}$ Bleed is caused by gastro-duodenal ulcers (gastric ulcers in $24.4 \%$ and duodenal ulcers $20.6 \%$, portal gastropathy in $14.4 \%$, Mallory Weiss tear in $11.3 \%$ and gastro-duodenal erosions in $10.6 \% .^{1}$ But, there has been a change in trend due to excessive use of proton pump inhibitors with portal hypertension emerging as a major cause of upper gastrointestinal bleeding. ${ }^{10,11}$

Endoscopy is the preferred diagnostic tool in all the cases of upper gastrointestinal bleeding. The initial assessment includes measurement of the blood pressure and heart rate, as well as blood tests to determine hemoglobin concentration. In significant bleeding, fluid replacement is often required, as well as blood transfusion, before the source of bleeding can be 
determined by endoscopy of the upper digestive tract with an esophagogastroduodenoscopy. Depending on the source, endoscopic therapy can be applied to reduce rebleeding risk. Specific medical treatments (such as proton pump inhibitors for peptic ulcer disease) or procedures (such as TIPS for variceal hemorrhage) may be used. Recurrent or refractory bleeding may lead to need for surgery, although this has become uncommon as a result of improved endoscopic and medical treatment. ${ }^{12}$ As there is a discrepancy among studies and literature so the rationale of conducting this study is to find out the most common causes of upper gastrointestinal bleeding so as to make a better use of hospital resources and take further preventive measures to reduce morbidity and mortality of these patients.

\section{METHODOLOGY}

Study Design: Descriptive, Cross-sectional study.

Settings: Department of Medicine, Allied Hospital, Faisalabad Pakistan.

Duration: $4^{\text {th }}$ April 2018 to $3^{\text {rd }}$ October 2018.

Sample Technique: Non-probability, consecutive sampling.

Sample Size:352 patients.

Inclusion Criteria: Patients presenting with hematemesis and/ or melena of any age or gender, having single or multiple episodes of $\mathrm{GI}$ bleed who had undergone endoscopy for these complaints were included.

Exclusion Criteria: Patients presenting with hematemesis and/ or melena but cannot undergo endoscopy due to Shock, Acute ischemic event, Peritonitis, Acute perforation, Fulminant colitis, Trauma to head and neck, Un-cooperative patients and Terminally ill were excluded.

Data Collection Procedure: After approval by ethical review committee and after taking informed consent from all the participants of study, patients who had undergone upper $\mathrm{GI}$ endoscopy due to upper gastro-intestinal bleeding were enrolled from emergency in the study who fulfilled the inclusion criteria. Endoscopy was performed by the senior gastroenterologists having minimum experience more than 5 years. Endoscopy was performed on fixed days during the study period of six months. Enrolled patients were advised to stay NPO for 6 hours and then were brought to endoscopy room of Allied Hospital, Faisalabad. After sterilization endoscope was introduced via oral cavity of the patient and the cause of bleed was diagnosed. All the data was entered in the proforma by the primary investigator immediately after endoscopy and then enlisted according to frequency of all causes.

Data Analysis Procedure: The data was analyzed by computer software SPSS version 21.0. Mean and standard deviation for age were calculated. The qualitative data like gender and peptic ulcer, varices, Mallory Weiss tear, vascular anomalies and gastro-duodenal erosions were labeled as frequency and percentage. Stratification was done to control effect modifiers. Post stratification chi-square test was applied to see the effect of these on outcome variable. $P$ value $\leq 0.05$ was considered as significant.
RESULTS

Mean age was $43.76 \pm 13.93$ years. Majority of the patients i.e. $204(57.95 \%)$ were between 20 to 45 years of age. Out of 352 patients, $239(67.90 \%)$ were males and $113(32.10 \%)$ were females with male to female ratio of 2.1:1 (Table 1).

Table 1: Distribution of patients according to age and gender $(n=352)$

\begin{tabular}{|c|c|c|}
\hline Variables & No. of Patients & \%age \\
\hline \multicolumn{3}{|c|}{ Age (groups) } \\
\hline $\mathbf{2 0 - 4 5}$ & 204 & 57.95 \\
\hline $\mathbf{4 6 - 7 0}$ & 148 & 42.05 \\
\hline Total & 352 & 100.0 \\
\hline \multicolumn{2}{|c|}{ Gender } \\
\hline Males & 239 & 67.90 \\
\hline Females & 113 & 32.10 \\
\hline Total & 352 & 100.0 \\
\hline
\end{tabular}

Mean $\pm S D=43.76 \pm 13.93$ years

The common causes of upper gastrointestinal bleeding in my study were found to be variceal bleeding in $183(51.99 \%)$, peptic ulcer in 84 (23.86\%), mallory-weiss tear in 41 (11.65\%), vascular anomalies in 11 (3.13\%) and gastro-duodenal erosions in $33(9.38 \%)$ patients (Fig 1).

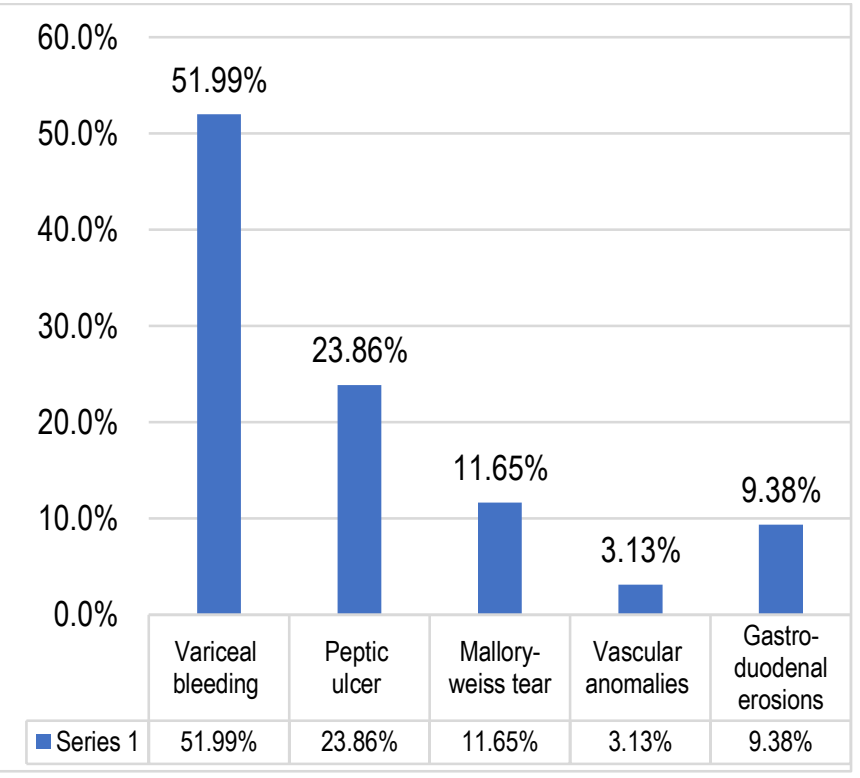

Figure 1: Common causes of upper gastrointestinal bleeding $(n=352)$

According to the stratification with respect to age, peptic ulcer and vascular anomalies were significantly associated with age $>45$ years, while gastro-duodenal erosions were significantly linked to the age of $<45$ years $p$-values were quite significant. Table 2 
Table 2: Stratification of Presentation with respect to age groups $(n=352)$

\begin{tabular}{|c|c|c|c|c|}
\hline \multicolumn{2}{|c|}{$\begin{array}{c}\text { Causes of upper } \\
\text { gastrointestinal bleeding }\end{array}$} & $\begin{array}{c}20-45 \\
\text { years } \\
(\mathrm{n}=204)\end{array}$ & $\begin{array}{c}46-70 \\
\text { years } \\
(n=148)\end{array}$ & $\begin{array}{l}\mathrm{P}- \\
\text { value }\end{array}$ \\
\hline \multirow{2}{*}{ Variceal bleeding } & Yes & 115 & 68 & \multirow{2}{*}{0.053} \\
\hline & No & 89 & 80 & \\
\hline \multirow{2}{*}{ Peptic ulcer } & Yes & 34 & 50 & \multirow{2}{*}{0.0001} \\
\hline & No & 170 & 98 & \\
\hline \multirow{2}{*}{ Mallory-weiss tear } & Yes & 25 & 16 & \multirow{2}{*}{0.677} \\
\hline & No & 179 & 132 & \\
\hline \multirow{2}{*}{ Vascular anomalies } & Yes & 02 & 09 & \multirow{2}{*}{0.007} \\
\hline & No & 202 & 139 & \\
\hline \multirow{2}{*}{$\begin{array}{l}\text { Gastro-duodenal } \\
\text { erosions }\end{array}$} & Yes & 28 & 05 & \multirow{2}{*}{0.001} \\
\hline & No & 176 & 143 & \\
\hline
\end{tabular}

According to the stratification with respect to the gender, variceal bleeding, ulcer and vascular anomalies were significantly associated with male gender ( $P=0.002$ and 0.007$)$ respectively. However, gastro-deudenal erosions were significantly associated with females $(p=0.004)$. Table. 3

Table 3: Stratification of Presentation with respect to gender $(n=352)$

\begin{tabular}{|l|c|c|c|c|}
\hline \multicolumn{1}{|c|}{$\begin{array}{c}\text { Causes of upper } \\
\text { gastrointestinal bleeding }\end{array}$} & $\begin{array}{c}\text { Male } \\
(\mathbf{n = 2 3 9 )}\end{array}$ & $\begin{array}{c}\text { Female } \\
(\mathbf{n = 1 1 3 )}\end{array}$ & $\begin{array}{c}\text { P- } \\
\text { value }\end{array}$ \\
\hline \multirow{2}{*}{ Variceal bleeding } & Yes & 138 & 45 & \multirow{2}{*}{0.002} \\
\cline { 2 - 4 } & No & 101 & 68 & \\
\hline \multirow{2}{*}{ Peptic ulcer } & Yes & 47 & 37 & \multirow{2}{*}{0.007} \\
\cline { 2 - 4 } & No & 192 & 76 & \\
\hline \multirow{2}{*}{ Mallory-weiss tear } & Yes & 29 & 12 & \multirow{2}{*}{0.679} \\
\cline { 2 - 4 } & No & 210 & 101 & \\
\hline \multirow{2}{*}{ Vascular anomalies } & Yes & 10 & 01 & \multirow{2}{*}{0.097} \\
\cline { 2 - 4 } & No & 229 & 112 & \\
\hline \multirow{2}{*}{$\begin{array}{l}\text { Gastro-duodenal } \\
\text { erosions }\end{array}$} & Yes & 15 & 18 & \multirow{2}{*}{0.004} \\
\cline { 2 - 4 } & No & 224 & 95 & \\
\hline
\end{tabular}

\section{DISCUSSION}

Upper gastrointestinal (GI) bleeding refers to blood loss within the intraluminal $\mathrm{GI}$ tract proximal to the ligament of Treitz. ${ }^{13}$ Upper $\mathrm{Gl}$ bleeding is a medical emergency that remains a common cause of morbidity and mortality worldwide. ${ }^{14,15}$ The incidence of upper $\mathrm{Gl}$ bleeding increases with age and is twice as common in males as in females. ${ }^{16,17}$ Bleeding from the upper $\mathrm{Gl}$ tract is approximately four times more common as bleeding from the lower GI tract. ${ }^{18}$ The etiology of upper GI bleeding varies significantly with geographic regions depending on the demographics and socioeconomic characteristics. ${ }^{19}$ Causes of upper $\mathrm{GI}$ bleeding could be variceal such as esophageal and gastric varices and nonvariceal such as peptic ulcer disease (PUD), erosive gastroduodenitis, reflux esophagitis, tumors and vascular ectasia. Identification of the cause of bleeding is important in effective management of the patient. Endoscopy of the upper GI tract is indeed the diagnostic modality of choice for acute upper GI bleeding with more sophisticated investigation such as angiography and computed tomography being rarely indicated where endoscopy is inconclusive. ${ }^{20}$

Previous studies in the northern part of Nigeria reported esophageal varices as the most common cause of upper $\mathrm{GI}$ bleeding, 21,22 while studies from Ekiti (Nigeria) ${ }^{23}$ and Ilorin (Nigeria $^{24}$ reported gastric erosions and multiple sources of bleeding, respectively, as their most common endoscopic findings. In developed countries, studies reported peptic ulcer as the most common cause of upper GI bleeding. ${ }^{25-27}$ Peptic ulcers remain one of the leading cause of upper gastrointestinal bleeding in West accounting up to $40 \%$ while portal hypertension being second leading cause with 10-20\% incidence. ${ }^{8}$ While according to a study conducted in Egypt variceal causes of bleeding were the most common representing $70.1 \%$ followed by non-variceal causes $26.1 \%$ and obscure causes $3.8 \% .{ }^{9}$ According to various other studies the 1 year rate of variceal bleeding is $12 \%$. Frequently Upper $\mathrm{GI}$ bleed is caused by gastro-duodenal ulcers (gastric ulcers in $24.4 \%$ and duodenal ulcers $20.6 \%$, portal gastropathy in $14.4 \%$, Mallory Weiss tear in $11.3 \%$ and gastro-duodenal erosions in $10.6 \%{ }^{1}$

The common causes of upper gastrointestinal bleeding in my study were found to be variceal bleeding in $183(51.99 \%)$, peptic ulcer in $84(23.86 \%)$, Mallory-Weiss tear in 41 (11.65\%), vascular anomalies in 11 (3.13\%) and gastro-duodenal erosions in $33(9.38 \%)$ patients. In a study ${ }^{28}$ on 1084 patients, the most common cause of upper $\mathrm{Gl}$ bleeding was peptic ulcer disease (PUD), found in 102 (32.8\%) cases, followed by gastritis in 88 (28.3\%) cases. Esophageal varices accounted for $47(15.1 \%)$ cases whereas duodenitis was found in $16(5.1 \%)$ cases. Carcinoma of the stomach occurred in $13(4.2 \%)$ cases while 12 (3.9\%) patients had esophagitis. Gastroesophageal reflux disease accounted for 11 (3.5\%) cases whereas esophageal ulcers occurred in $3(1.0 \%)$ cases. Carcinoma of the esophagus and esophageal candidiasis each constituted $2(0.6 \%)$ cases. The cause of bleeding was not found in $15(4.8 \%)$ patients. ${ }^{28}$ In a local study, ${ }^{29}$ there were 174 males $(71.3 \%)$ and 70 females (28.7\%). The age of the patients ranged from 15 years to 75 years, mean age was 52.23 years $(S D=14.78)$. The most common cause of upper $\mathrm{GI}$ bleed was varices in 176 (72.1\%) patients; followed by gastric ulcer in $24(9.8 \%)$ patients. Other causes in order of decreasing frequency included gastritis 16 (6.55\%), duodenal ulcer 14(5.73\%), esophagitis $6(2.45 \%)$, Mallory Weiss tear $2(0.81 \%)$ and miscellaneous $6(2.45 \%)$.In a study conducted by Barkun et al in most settings, the vast majority of acute episodes of upper gastrointestinal bleeding (80 to $90 \%$ ) have non-variceal causes, with peptic ulcer accounting for the majority of lesions. ${ }^{30}$ In another study conducted by Laine, varices accounts for 10 to 30 percent of all cases of bleeding from the upper gastrointestinal tract. ${ }^{31}$

In another local study, ${ }^{32}$ out of 100 patients selected, 51 (51\%) were males and $49(49 \%)$ females. Majority of patients were between $30-60$ years with mean age of 43.97 years \pm SD 7.8. 
Variceal bleed was the most common cause $n=54(54 \%)$ followed by peptic ulcer disease (PUD) $n=20(20 \%)$. Esophagitis was noted in ten (10\%) patients, gastric erosions in nine $(9 \%)$, tumors of upper gastrointestinal tract in six $(6 \%)$ and MalloryWeiss tear was responsible in only one $(1 \%)$ cases. ${ }^{32}$

In another study, ${ }^{33}$ the records of 106 patients who underwent endoscopy for upper $\mathrm{GI}$ bleeding over a period of 6 years (20032008) were retrospectively analyzed. A total of 106 patients were studied. Seventy-four $(69.8 \%)$ were males while 32 $(30.2 \%)$ were females. Their ages ranged from 14 to 75 years with a mean of $41.2( \pm 15.1 \mathrm{SD})$ years. Oesophageal varices were the most frequent cause of bleeding $(45.3 \%)$ followed by erosive mucosal disease (23.7\%) and peptic ulcer disease (16.9\%). Gastric cancer and Mallory-Weiss syndrome were rare with each accounting for $1.9 \%$ of the cases. In 11 (10.4\%) patients no source of bleeding could be identified. ${ }^{33}$

\section{CONCLUSION}

This study concluded that the variceal cause is the most common cause of upper gastrointestinal bleeding followed by peptic ulcer and Mallory-Weiss tear. So, we recommend that clinicians should take great care of the upper gastrointestinal bleeding patients and take early management for saving these patients life.

\section{LIMITATIONS}

As Endoscopic diagnosis is operator dependent, this may be considered as a limitation of this study.

\section{SUGGESTIONS / RECOMMENDATIONS}

As variceal bleeding is the most common cause of Upper $\mathrm{GI}$ Bleed in majority of studies, we recommend health authorities to implement Upper GI endoscopy in all cirrhotic patients as this is a diagnostic and therapeutic procedure that may reduced mortality and morbidity.

\section{CONFLICT OF INTEREST / DISCLOSURE}

There is no conflict of interest in this study.

\section{ACKNOWLEDGEMENTS}

We are thankful to all the postgraduate residents of Medical Unit-III, Allied Hospital Faisalabad who helped us in selecting the patients presenting with Upper GI Bleed in Emergency.

\section{REFERENCES}

1. Hadayat R, Jehangiri AU, Gul R, Khan AN, Said K, Gandapur A. Endoscopic Findings of Upper Gastrointestinal Bleeding in Patients with Liver Cirrosis. J Ayub Med Coll Abbottabad. 2015;27(2):391-4.

2. Laine L. Gastrointestinal bleeding. In: Longo DL, Kasper DL, Jameson DL, Fauci AS, Hauser SL, Loscalzo J, et al, editors. Harrison's Principles of Internal Medicine. 18th Ed. New York: McGraw-Hill; 2012:320-3.

3. Sánchez-Delgado J, Gené E, Suárez $D$, et al. Has $H$. pylori prevalence in bleeding peptic ulcer been underestimated? A meta-regression. Am J Gastroenterol. 2011;106(3):398-405.
4. Jairath $\mathrm{V}$, Desborough MJ. Modern-day management of upper gastrointestinal haemorrhage. Transfus Med. 2015;25(6):351-7.

5. Barkun AN, Almadi M, Kuipers EJ, Laine L, Sung J, Tse F, et al. Management of Nonvariceal Upper Gastrointestinal Bleeding: Guideline Recommendations from the International Consensus Group. Ann Intern Med. 2019;171(11):805-22.

6. Kärkkäinen JM, Miilunpohja S, Rantanen T, Koskela JM, Jyrkkä $\mathrm{J}$, Hartikainen J, et al. Alcohol Abuse Increases Rebleeding Risk and Mortality in Patients with Non-variceal Upper Gastrointestinal Bleeding. Dig Dis Sci. 2015;60(12):3707-15.

7. Papadakis MA, Mcphee SJ. Current Medical Diagnosis and treatment $55^{\text {th }}$ Edition, McGrawhill Education; 2016;584-7.

8. McQuaid KR. Gastrointestinal disorders. In: Papadakis MA,McPhee SJ, Rabow MW, editors. Current medical diagnosis and treatment. 52nd Ed. New York: McGraw-Hill; 2013:564-661.

9. Elwakil R, Reda MA, Abdelhakam SM, Ghoraba DM, Ibrahim WA. Causes and outcome of upper gastrointestinal bleeding in emergency endoscopy unit of Ain Shams University Hospital. J Egypt Soc Parasitol. 2011;41:455-67.

10. Kim JJ, Sheibani S, Park S, Buxbaun J, Laine L. Causes of bleeding and outcomes in patients hospitalized with upper gastrointestinal bleeding. J Clin Gastroenterol. 2014;48:113-8.

11. Kim JJ, Sheibani S, Park S, Buxbaum J, Laine L. Causes of bleeding and outcomes in patients hospitalized with upper gastrointestinal bleeding. J Clin Gastroenterol. 2014;48(2):113-8.

12. Chavez-Tapia NC, Barrientos-Gutierrez T, Tellez-Avila FI, Soares-Weiser K, Uribe M. Antibiotic prophylaxis for cirrhotic patients with upper gastrointestinal bleeding. Cochrane Database Syst Rev. 2010;(9):CD002907.

13. Jaka H, Koy M, Liwa A, Kobangila R, Mivambo M, Scheppach, et al. A fibreoptic endoscopic study of upper gastrointestinal bleeding at Bugando Medical Centre in North Western Tanzania: A retrospective review of 240 cases. BMC Res Notes 2012;5:200.

14. Sarin N, Monga N, Adams PC. Time to endoscopy and outcomes in upper gastrointestinal bleeding. Can J Gastroenterol 2009;23:489-93.

15. Elghuel $A$. The characteristics of adults with upper gastrointestinal bleeding admitted to Tripoli Medical Center: A retrospective case-series analysis. Libyan J Med 2011;6:6283.

16. Jutabha R, Jensen DM. Management of upper gastrointestinal bleeding in the patient with chronic liver disease. Med Clin North Am. 1996;80:1035-68.

17. Longstreth GF. Epidemiology of hospitalization for acute upper gastrointestinal hemorrhage: A population-based study. Am J Gastroenterol 1995;90:206-10.

18. Palmer K. Management of haematemesis and melaena. Postgrad Med J 2004:80:399-404.

19. Theocharis GJ, Thomopoulos KC, Sakellaropoulos G, Katsakoulis E, Nikolopoulou V. Changing trends in the epidemiology and clinical outcome of acute upper gastrointestinal bleeding in a defined geographical area in Greece. J Clin Gastroenterol 2008;42:128-33.

20. Tijjani BM, Borodo MM, Samaila AA. Endoscopic findings in patients with upper gastrointestinal bleeding in Kano, NorthWestern Nigeria. Niger Hosp Pract 2009;4:43-5.

21. Malu AO, Wali SS, Kazmi R, Macauley D, Fakunle YM. Upper gastrointestinal endoscopy in Zaria, Northern Nigeria. West Afr J Med 1990;9:279-84.

22. Mustapha S, Ajayi N, Shehu A. Aetiology of upper gastrointestinal bleeding in North-Eastern Nigeria: A retrospective endoscopic study. Internet J Third World Med 2009;8:2. 
23. Oladiniyi AA, Temi AP, Adekunle AE, Abidemi SO, Olatayo AA, Abayomi AM. Aetiology and Management Outcome of Upper Gastrointestinal Bleeding in Adult patients Presenting at Ekiti State University Teaching Hospital, Ado-Ekiti, Nigeria. Greener JMedi Sci. 2013;3:93-7.

24. Olokoba $A B$, Olokoba LB, Jimoh $A A$. Upper gastrointestinal tract bleeding in llorin, Nigeria - A report of 30 cases. Niger J Clin Pract 2009;12:240-4.

25. Rockall TA, Logan RF, Devlin HB, Northfield TC. Incidence of and mortality from acute upper gastrointestinal haemorrhage in the United Kingdom. Steering committee and members of the national audit of acute upper gastrointestinal haemorrhage. BMJ 1995;311:222-6.

26. Vreeburg EM, Snel P, de Bruijne JW, Bartelsman JF, Rauws EA, Tytgat GN. Acute upper gastrointestinal bleeding in the Amsterdam area: Incidence, diagnosis, and clinical outcome. Am J Gastroenterol 1997;92:236-43.

27. Zaltman C, Souza HS, Castro ME, Sobral Mde F, Dias PC, Lemos V Jr. Upper gastrointestinal bleeding in a Brazilian hospital: A retrospective study of endoscopic records. Arq Gastroenterol 2002;39:74-80.

28. Ugiagbe RA, Omuemu CE. Etiology of upper gastrointestinal bleeding in the University of Benin Teaching Hospital, SouthSouthern Nigeria. Niger J Surg Sci 2016;26:29-32

29. Sher F, Ullah RS, Khan J, Mansoor SN, Ahmed N. Frequency of different causes of upper gastrointestinal bleeding using endoscopic procedure at a tertiary care hospital. Pak Armed Forces Med J. 2014;64(3):410-3.

30. Barkun A, Sabbah S, Enns R. The Canadian Registry on Nonvariceal Upper Gastrointestinal Bleeding and Endoscopy (RUGBE): endoscopic hemostasis and proton pump inhibition are associated with improved outcomes in a real-life setting. Am J Gastroenterol. 2004; 99:1238-46.

31. Laine L. Upper gastrointestinal tract hemorrhage. West J Med. 1991;155:274-9.

32. Ghouri A, Kumar S, Bano S, Aslam S, Ghani MH. Endoscopic Evaluation of Upper Gastrointestinal Bleeding in Patients Presenting with Hematemesis within 24 Hours of Admission. J Liaquat Uni Med Health Sci. 2016;15(04):174-8.

33. Mustapha S, Ajayi N, Shehu A. Aetiology Of Upper Gastrointestinal Bleeding in North-Eastern Nigeria: A Retrospective Endoscopic Study. Internet J Third World Med 2008;8:2.

\section{AUTHORSHIP CONTRIBUTION}

\begin{tabular}{|l|l|}
\hline $\begin{array}{l}\text { Dr. Muhammad Amir } \\
\text { Assistant Professor of Medicine, } \\
\text { Faisalabad Medical University, } \\
\text { Faisalabad Pakistan }\end{array}$ & $\begin{array}{l}\text { Study Design, Data Analysis, } \\
\text { Manuscript Writing, Results } \\
\text { Compilation }\end{array}$ \\
\hline $\begin{array}{l}\text { Dr. Sarah Hafeez } \\
\text { Post Graduate Resident, Department of } \\
\text { Medicine, Allied Hospital, Faisalabad } \\
\text { Pakistan }\end{array}$ & $\begin{array}{l}\text { Data Collection, References } \\
\text { Collection }\end{array}$ \\
\hline $\begin{array}{l}\text { Dr. Muhammad Adrees } \\
\text { Assistant Professor of Medicine, } \\
\text { Faisalabad Medical University, } \\
\text { Faisalabad Pakistan }\end{array}$ & $\begin{array}{l}\text { Conception \& Designing, } \\
\text { Data Analysis }\end{array}$ \\
\hline $\begin{array}{l}\text { Dr. Amir Nazir } \\
\text { Associate Professor of Medicine, } \\
\text { Sargodha Medical College, Sargodha } \\
\text { Pakistan }\end{array}$ & $\begin{array}{l}\text { Critical Review of the Article, } \\
\text { Proof Reading }\end{array}$ \\
\hline $\begin{array}{l}\text { Dr. Hafiz Mughees Ather } \\
\text { Associate Professor, Gastroenterology } \\
\text { Faisalabad Medical University, } \\
\text { Faisalabad Pakistan }\end{array}$ & $\begin{array}{l}\text { Comparison of Results with } \\
\text { Other Studies, Final Editing }\end{array}$ \\
\hline
\end{tabular}

